\title{
A Biotechnological Approach to Apoptosis of Somatic and Germ Cells in Living Organisms
}

\author{
Surabhi Nanda ${ }^{1}$, Sanjay Mishra ${ }^{1, *}$, V.P. Varshney ${ }^{2}$ and R.B. Singh ${ }^{3}$ \\ ${ }^{I}$ Department of Biotechnology, College of Engineering and Technology, IFTM Campus, Moradabad, UP, India \\ ${ }^{2}$ Physiology \& Climatology Division, Indian Veterinary Research Institute, Izatnagar 243112, U.P., India \\ ${ }^{3}$ Halberg Hospital and Research Institute, Civil Lines, Moradabad 244 001, U.P., India
}

\begin{abstract}
Apoptosis or programmed cell death (PCD) is known for defense and developmental mechanisms. A remarkable overlap has been suggested between the hallmarks of PCD in plants and animals in spite of identification of very few regulatory proteins or protein domains conserved across all eukaryotic PCD forms. The features like chromatin condensation, nuclear DNA fragmentation, and participation of caspase like proteases in plant PCD appear to be similar across the board and in conformity with the process in metazoans as well. Transgenic expression of mammalian anti- and proapoptotic proteins in plants influence the regulatory pathways of cell death activation and suppression, indicating the existence of functional counterparts of such genes in plants, several of which have now been cloned and characterized to various extents, suggesting that despite differences, there may be a fair level of functional similarity between the mechanistic components of plant and animal apoptosis. The overall review of the available data pertaining to mechanism of PCD in plants is at best inclined to support an ancestral relationship with animal apoptosis rather than any common regulational strategies. Besides, as far as germ cell apoptosis is concerned, 'Abortive Apoptosis' is a theory that still requires much scientific evidence to be considered valid. Because of naturally occurring processes within the spermatozoa that mimic somatic cell apoptosis, many believe that this theory requires additional evidence. Oxidative Stress Oxidative stress upon spermatozoa is induced by an increase in the amount of reactive oxygen species (ROS) that are present in the fluids filling the male genital tract.
\end{abstract}

Keywords: Apoptosis, Caspases, Conserved domain, Bax-1 inhibitor, Regulatory pathway, germ cell population, male germ cell homeostatis, defective sperm chromatin packaging.

\section{INTRODUCTION}

Apoptosis describes a physiological and pathological process of cell deletion that plays an important role in maintaining tissue (somatic and germ) homeostasis [1-5]. It is a highly regulated cellular suicide process essential for growth and survival in all eukaryotes. The origin of the phenomenon seems to be as old as the very first cell, because cellular homeostasis and preventing self-destruction would have been impossible to accomplish without such machinery [6]. Therefore, this apparatus appears to have existed in all cells from the very origin. It has, indeed, been recognized in several prokaryotes and unicellular eukaryotes and related to numerous phenomena. Only later, during evolution of multicellular organisms, PCD is believed to have 'fine tuned' for purposes such as the social control of cell members [7]. Multicellular organisms use the physiological mechanisms of cell death to regulate developmental morphogenesis and remove infected, mutated or damaged cells from healthy tissues [8]. This phenomenon is characterized in detail, especially in animal apoptosis systems, by a

*Address correspondence to this author at the Department of Biotechnology \& Dean (Research), College of Engineering \& Technology, IFTM Campus, Delhi Road, Moradabad 244 001, UP, India; Tel/Fax: +0091-591-2360818; E-mail: sanjaymishra66@gmail.com stereotypical set of morphological and biochemical changes such as condensation or shrinkage of the cell, reorganization of the nucleus, membrane blebbing, formation of apoptotic bodies [9] and chromatin condensation [10-13]. This process finally results in activation of certain endonucleases, leading to the fragmentation of chromatin in multiples of $180-\mathrm{bp}$ nucleosomal units, a process known as DNA laddering [10, 14-17]. Most, but not all, of the above apoptotic features are commonly observed during PCD in a wide range of eukaryotic organisms.

Apoptosis is the controlled disassembly of a cell from within [18]; it is believed to have 2 roles during normal spermatogenesis [19-21]. The first role is to limit the germ cell population to numbers that can be supported by the surrounding Sertoli cells. The second is for the depletion of abnormal spermatozoa. As seen in the prior section, abnormal spermatozoa can be produced via defective sperm chromatin packaging, among other ways. In somatic cells, cells that enter into an apoptotic pathway usually have several classical indicators, such as phosphatidylserine (PS) relocation, Fas expression, nDNA strand breaks, and caspase activity. PS relocation is perhaps the earliest indicator of apoptosis; normally located on the inner leaflet of the plasma membrane, PS migrates to the outer membrane once the apoptotic signal has been given [18]. To help control this signal, both 
pro- and anti- apoptotic proteins are present in the testis; they are members of the Bcl-2 family of proteins and provide a signaling pathway that is imperative to maintaining male germ cell homeostasis [21]. Bcl-2 and Bcl-xL are both prosurvival proteins, while Bax is a pro-apoptotic protein. Disturbing the balance of these proteins from the $\mathrm{Bcl}-2$ family has been demonstrated in mice to contribute to male infertility by disrupting normal apoptosis levels. Fas expression is another indicator that the apoptosis signal has been given. Fas is a type I cell surface protein, belonging to the tumor necrosis/nerve growth factor receptor family [18]; it is induced by the binding of Fas ligand to the Fas receptor on the plasma outer membrane. Sertoli cells are known to express Fas ligand, demonstrating the fact that apoptosis is a commonly used mechanism to control the germ cell population at a level that can be supported by the Sertoli cells [22]. Ligation of Fas ligand to the Fas receptor triggers activation of cytosolic aspartate-specific proteases, or simply caspases. Once caspase activation has taken place, a signal is transduced to synthesize caspase-activated deoxyribonuclease, which leads to DNA degradation by forming singleand double-stranded breaks within the nDNA [23]. In infertile men, ejaculated spermatozoa often possess partially degraded nDNA, usually considered to be indicative of the apoptosis pathway; this "escaping" of the apoptosis signal is referred to as "abortive apoptosis" [22, 24, 25] The apoptotic pathway is an all or nothing response, meaning that once the signal has been given there is no reversing the process. Abnormalities in this pathway are often attributed to 1 of 2 possibilities: infertile men may not produce enough sperm to trigger Sertoli cell activation to produce Fas, or there may be a problem in activating the Fasmediated apoptosis signal [23]. It is believed that if the apoptotic cascade is initiated at the round spermatid phase when transcription is still active, this may be the origin of the nDNA breaks commonly seen in abortive apoptosis in ejaculated spermatozoa. However, nDNA breaks are known to be common during condensation of the genome. It is currently unclear whether these breaks are caused by an aborted apoptotic pathway or simply by incomplete chromatin packaging. Also, not all caspase activity has been shown to be indicative of the apoptotic signal. Recent work has demonstrated that there appears to be some caspase activity in human germ cells that is not associated with apoptosis and may indeed serve a viable function [26]. Another well-known inducer of the apoptotic pathway is telomere shortening. Telomeres are capping structures at chromosome ends that protect against rearrangements, preventing ends from being recognized as nDNA breaks [27]. They are usually composed of tandem TTAGGG sequence repeats that are bound to a complex array of proteins. Telomerase is a specialized reverse transcriptase that contains a catalytic subunit that synthesizes new telomeric repeats. In the absence of telomerase, telomeric sequences are lost after each round of replication, eventually creating a shifted sequence that could be recognized as an nDNA doublestranded break; this would then be recognized by a genomic surveillance mechanism that appears in the elongating spermatid [27]. This recognition is another way to induce an apoptotic response, possibly contributing to the "abortive apoptosis" theory. Abortive apoptosis is a theory that still requires much scientific evidence to be considered valid. Because of naturally occurring processes within the sper- matozoa that mimic somatic cell apoptosis, many believe that this theory requires additional evidence. Oxidative Stress Oxidative stress upon spermatozoa is induced by an increase in the amount of reactive oxygen species (ROS) that are present in the fluids filling the male genital tract [28].

In plants, PCD occurs during development, such as during xylogenesis, embryogenesis, parenchyma formation, several plant reproductive processes, seed development and leaf senescence [7, 29-34]. In addition, PCD is well documented in relation to manifestation of hypersensitive response (HR) caused by the interaction between the host plant and an incompatible pathogen [35]. This hypersensitive response (HR) is thought to directly kill invaders and/or to interfere with their acquisition of nutrients [36]. In contrast to animal system, signaling pathways and molecular mechanism of PCD are largely unknown in plants. Although a number of morphological and biochemical changes such as cell shrinkage, blebbing of the plasma membrane, condensation and fragmentation of the nucleus, and inter-nucleosomal cleavage of DNA, which are commonly observed during animal apoptosis, appear to be conserved in plant cells undergoing PCD, very little is known about the execution process that leads to cell death in plants.

In this review we provide a brief insight into some of the comparative features of PCD in plants and animals. Additionally, this article attempts to review some of the peculiar and specific features and regularities of apoptosis in somatic as well as germ cells in plants and animals.

\section{MORPHOLOGICAL HALLMARKS OF PCD}

The morphological features of PCD have been intensively studied in animals. PCD in animal systems is reported to result in the disassembly of cells involving the condensation, shrinkage and fragmentation of cytoplasm and nuclei into several sealed packets (often called apoptotic bodies), which are then phagocytosed, by the neighboring cells or the macrophages. Thus, there are no remnants of the cell corpses left. Nuclear fragmentation is preceded by chromatin condensation and marginalization in the nucleus. Fragmentation of DNA at the nucleosome linker sites then takes place and the fragmented oligonucleosomal bits are reported to be 180 bp [37]. Fragmentation is effected by endonucleases such as NUC 1, DNaseI and DNaseII [38], which are present in the nucleus and are activated by $\mathrm{Ca}^{2+}$ and $\mathrm{Mg}^{2+}$ but inhibited by $\mathrm{Zn}^{2+}$ and by several caspase activated nucleases such as CAD (Caspase activated DNase) or DFF40 (DNA fragmentation factor $40 \mathrm{KDa}$ ) [39-41]. The DNA fragments can be cytochemically determined by Terminal deoxynucleotidyl transferase mediated dUTP Nick End Labelling (TUNEL) of DNA at 3'-OH group. When all these events are combined to result in a distinct morphological expression then PCD is termed as apoptosis [42]. In other words, apoptosis is a distinct form of PCD [43, 44]. However there are others who consider apoptosis and PCD as one and the same [45-48].

In the last few years and due to new interest in a possible apoptosis like phenomenon existing in plants, morphological changes have been investigated during plant PCD. Only some of the hallmarks are similar to those reported in animal apoptosis. Condensation and shrinkage of the cytoplasm and 
nucleus have been described in carrot cell culture, after cell death induced by heat shock [16]. The DNA processing reported earlier for the animal PCD is believed to exist in the dying cells of plant as well $[15,16,49,50]$. In plants, DNA ladders have been reported during development represented by death of monocot aleurone layer [49] and endosperm [51], senescence of petal, carpel tissue and leaves [50,52, 53] or during anther development [54] as well as during death induced by different stresses such as: cold [55], nutrient deprivation [56], salt or D-mannose stresses [57, 58], UV radiation [37], pathogens or a pathogen toxin [54, 59, 60]. In aleuronic cells of grass species such as barley, in dying root cap cells and in tobacco cells subjected to HR, nuclear condensation and shrinkage as well as oligonucleosome sized DNA fragments have been recognized through the presence of 3'-OH group detected by TUNEL experiments [34, 61]. The major problem relating to nuclear changes in plant PCD is that there is no consistency regarding the size of DNA fragments during DNA fragmentation: fragments of more or less $50 \mathrm{~Kb}$ in some cases [61] and as small as $0.14 \mathrm{~Kb}$ in others $[11,42]$. It is believed that the activation of some endonucleases leads to $50 \mathrm{~Kb}$ DNA fragments followed latter by a different set of endonucleases causing the production of oligonucleosomal length of DNA fragments [62]. The first type of cleavage is believed to be the result of the release of chromatin loops and is observed in almost all cases of apoptosis and the subsequent nucleosomal laddering occurs less often and is considered to be not essential for apoptosis [63].

The enzymes involved in nuclear dismantling in plants are still poorly known. Several DNase activities and nuclease genes have been recognized to be upregulated in different models of plant PCD [64]. However, evidence on their involvement in the cell death has been reported only in some of them. Recent work reported the induction of the activity of a $28 \mathrm{KDa}$ endonuclease (p28) activity in victorin [65] treated oat leaves and this preceded the DNA laddering and heterochomatin condensation. The p28 activity also markedly increased in parallel with the rate of DNA fragmentation and cell death [65]. In addition to p28, an inducible nuclease, p24 (24 kDa) and four constitutive nucleases, p22 (22 $\mathrm{kDa}), \mathrm{p} 31(31 \mathrm{kDa}), \mathrm{p} 33(33 \mathrm{kDa})$ and p35 (35 kDa), have been detected in oat cell lysates using an in-gel assay for nuclease activity $[65,66]$. An $\mathrm{Mg}^{2+}$ dependent nucleolytic activity has been identified in the intermembrane space of mitochondria responsible for the generation of $30 \mathrm{~Kb}$ DNA fragments in Arabidopsis [67]. ZEN1, a $\mathrm{Zn}^{2+}$ dependent endonuclease, has been directly implicated in the degradation of the nuclear DNA in Zinnia tracheary elements [67]. ZEN1 is localized to vacuoles, which collapse before DNA is degraded [68]. However, ZEN1 activity does not produce the characteristic DNA laddering shown by the nucleases executing DNA fragmentation in apoptotic animal cells [39-41]. Based on the biochemical differences of ZEN1 and the nucleases involved in apoptosis [67], it has been proposed that plants and animals have evolved independent systems of nuclear DNA degradation during cell death. In contrast with tracheary elements, the tissues undergoing PCD in cereal grains show the characteristic DNA laddering indicative of internucleosomal fragmentation of DNA [69-71], which is a hallmark of apoptosis in animal cells [10]. Recently, a $\mathrm{Ca}^{2+} / \mathrm{Mg}^{2+}$ endonuclease localized in the nucleus wheat aleuron cells undergoing PCD has been identified which is detected prior to DNA laddering [71]. A cell-free system used to analyse nucleus degeneration in nucellar cells in wheat grains [72], shows that a different wheat tissue, the nucellus, which undergoes PCD at early stage of grain development [70], presents a nucleus localized nuclease with identical cation requirements, but with a different electrophoretic mobility than the aleuron nuclease. These results suggest that, as in animal apoptosis [73], there is more than one nuclease involved in plant PCD. Nuclear extracts from such cells have been shown to be capable of triggering DNA fragmentation in both plant and human nuclei, demonstrating that similar features of nucleus degradation could be shared between plant and animal cells.

Apoptotic bodies have not been shown to form during plant cell death. These bodies may be absent in plant PCD because they are functionally irrelevant due to the absence of possible phagocytosis by adjacent cells in the presence of cell wall. Instead, the plant pathway might involve autolysis. Although cells that die as part of the HR typically exhibit features of an oncotic cell death, which is characterized by the retention of a dead protoplast containing swollen organelles [74], many other plant cell suicide programs include cellular disassembly via autophagy and/or autolysis. The degree of processing of dead and dying cells ranges from that apparently limited to nucleus or nuclear DNA to complete autolysis that includes the extracellular matrix. Degradation of nucleus and nuclear DNA has been evaluated in several recent investigations of plant PCD. The results are consistent with earlier work in a variety of systems. They include reports of nuclear blebbing and fragmentation [75$77]$, and the detection of oligosomal DNA ladders [75, 76, $78,79]$ and labelled fragmented DNA in nucleus [75, 76, 80, 81].

Autophagy has been observed as engulfment and degradation of nucleus and other organelles by provacuoles, vacuoles and other autophagic organelles derived from leucoplast [75]. Autolysis does not require engulfment and contributes to the degradation of organelles and soluble cellular components. Unlike autophagy, autolysis can continue after cell death, as occurs during treachery element differentiation. In most cases, autolysis and autophagic mechanisms cooperate to yield cellular disassembly, such as that occurring during embryo suspensor death [75]. So if using a strict morphological definition, the term apoptosis-like phenomenon in plants should be used instead of apoptosis since some of the terminal hallmarks of apoptosis are absent.

\section{FUNDAMENTAL EXECUTORS OF PCD}

The real effector molecules of animal PCD are the cysteine aspartate specific proteases (caspases) and granenzymes. The former are the conserved cysteine proteases, while the latter are serine proteases, both specifically cleave after the aspartate residues of many proteins. The studies in Caenorhabditis elegans identified two genes ced-3 and ced-4 required for apoptosis in the worm, if either gene is inactivated by mutation, the 131 cell deaths that normally happen during the development of the worm (which has only about 1000 cells when mature) fail to occur [82]. Remarkably, the 
mutant worms with 131 extra cells have a normal life span, showing that in this organism apoptosis is not essential for either life or normal ageing. By contrast, more complex animals cannot survive without apoptosis: mutations that inhibit apoptosis in the fruitfly Drosophila melanogaster, for example, are lethal early in development [83] as are mutations in mice that inhibit apoptosis mainly in the developing brain [84]. The protein encoded by the ced-3 gene was found to be very similar to a human protein called interleukin-1converting enzyme (ICE) [85]. ICE is an intracellular protein cleaving enzyme (a protease) that cuts out interleukin-1, a signalling protein that induces inflammation, from a larger precursor protein [86]. The similarity between the CED-3 and ICE proteins was the first indication that the death programme depends on protein cleavage (proteolysis). Till date 14 to 15 different caspases that play a role in inflammation (group1 caspases) and apoptosis (group 2 caspases ) have been identified in animals [87]. All these are believed to share a fair level of sequence homology and similarity in sequence specificity [86-88]. Until now, the caspase family in animals is composed of 12 different proteases classified in 3 phylogenetic groups [Interleukin $1 \beta$ converting Enzyme (ICE), ICH1 and cysteine protease 32 (CPP32)]. All these caspases have in common a highly conserved catalytic site, a stringent substrate specificity to cleave after an aspartic acid residue and requirement for at least 4 amino acids $\mathrm{N}$ terminal to cleavage site [89]. It is possible to classify these caspases on the basis of their affinity for different substrates including two tetrapeptides in particular: DEVD (ICH1 and CPP32) and YVAD (ICE caspases). Corresponding caspase activity can be blocked with same peptide substrate coupled with aldehyde (CHO: reversible inhibitor) or methyl ketone radical [Chlorometylketone (CMK), flouromethylketone (FMK): irreversible inhibitor). Caspases are made as a large, inactive precursor (procaspase), which is itself activated by cleavage at aspartic acids, usually by another caspase [90]; (Fig. 1). In apoptosis, caspases are thought to be activated in an amplifying proteolytic cascade, cleaving one another in sequence. Once activated, the effector caspases ultimately cleave numerous substrates, thereby causing the typical morphological features of apoptosis [91, 92]. They cleave proteins supporting the nuclear membrane (lamins) for example, thereby helping to dismantle the nucleus; they cleave protein constituents of the cell skeleton and other proteins involved in the attachment of the cell to their neighbors, thereby helping the dying cell to detach and round up making it easy to ingest; they cleave a protein Inhibitor of Caspase Activated DNase (ICAD of CAD-ICAD complex) that normally holds the CAD- a DNA degrading enzyme in an inactive form, freeing the DNase to cut up the DNA in the cell nucleus [39]. The other important substrates include PARP [poly(ADP-ribose)polymerase], DNA dependent protein kinase (DNA PK), Serum response element binding protein (SRE/BP), p21(CDKN1A)-activated kinase 2 (PAK2), $70 \mathrm{KDa}$ components of U1Sn-RNP, procaspases and so on [87]. PARP is among the first target proteins shown to be specifically cleaved by caspases to a signature of $89 \mathrm{KDa}$ apoptotic fragments during cell death [93]. It is believed to be involved in the regulation of the repair of DNA strand breaks and in cell recovery from DNA damage [90].

Cell death in plants exhibits morphological features comparable to caspase mediated apoptosis in animals, suggesting that plant cell death is executed by (caspase like) proteases. The recent characterization of cell death associated plant proteases with aspartate specific cleavage activity demonstrates the involvement in plant PCD of proteolytic activities functionally resembling animal caspases. The result of a study carried out show induction of YVADase activity whereas no DEVDase activity was detected [94]. Surprisingly, both inhibitor peptides (DEVD and YVAD) were efficient in blocking the HR and YVADase activity. Encouragingly, none of the classical protease activity could suppress the hypersensitive response or YVADase activity. This is cited as an evidence for the presence of caspase like plant proteases that participate in hypersensitive response cell death. Different results were found during the plant response to UV-C radiation where both caspase inhibitors could prevent DNA digestion detected by TUNEL reaction and where UV-C induced DEVDase activity but no YVADase activity was found. The heterologous expression of Baculovirus p35 protein, a broad range caspase inhibitor that can effectively suppress PCD in animals [44, 95], blocked AAL (Arternaria alternata) toxin induced cell death in transgenic tomato plants and provided protection against the pathogen Arternaria alternata. Additionally, p35-expressing transgenic tomato plants displayed partial inhibition of cell death associated with non-host hypersensitive response cell death upon bacteria and virus challenge [96]. Because p35 shows a high degree of specificity towards caspases and it shows a little or no inhibitory activity towards other proteases, these physiological inhibitor studies support an important role for caspase like proteases during cell death in plants [96]. In addition, natural caspase substrates such as bovine and plant PARP are cleaved by plant proteases at caspase cleavage sites. Exogenous (bovine) PARP is endoproteolytically cleaved by extracts from fungus-infected cowpea (Vigna unguiculata) plants that were developing a HR but not by extracts from noninfected leaves. This cleavage activity inhibited by caspase-3 inhibitor (Acetyl-DEVD-CHO) but not by caspase1 inhibitor (Acetyl-YVAD-CHO) [43]. Interestingly, a polypeptide (GDEVDGIDEV) mimicking the PARP caspase-3 cleavage site (DEVD-G) partially inhibited PARP cleavage, whereas a modified peptide in which the essential Asp was replaced by Ala (GDEVAGIDEV) did not affect PARP cleavage. This cleavage activity was also inhibited by other Cys protease inhibitors (E-64, IA, and N-ethylmaleimide). Inhibitors to other types of proteases (Ser-, metallo-, Asp proteases, and calpain) were without effect in this system. In these experiments, PARP cleavage eventually yielded four different fragments of 77, 52, 47, and $45 \mathrm{kD}$ [43]. Cleavage of endogenous (plant) PARP $(116 \mathrm{KDa})$ reacting with a PARP antibody occur during menadione-induced PCD in tobacco protoplasts, and this cleavage of PARP and induction of DNA fragmentation has been shown to be inhibited by caspase-1 (Acetyl-YVAD-CHO) and caspase-3 (AcetylDEVD-CHO) inhibitors [97]. Also in heat shock induced PCD in tobacco suspension cells, endogenous PARP was cleaved, yielding a $89-\mathrm{kDa}$ fragment [98]. This is similar to the cleavage of PARP described in animal apoptotic cells. In both mammals and plants, two different types of PARP exist, and both types are presumably involved in DNA repair. The Arabidopsis PARP-1 shows high homology to human PARP-1 including a conserved caspase-3 recognition site (DSVD-N). In plants, PARP genes have been cloned 


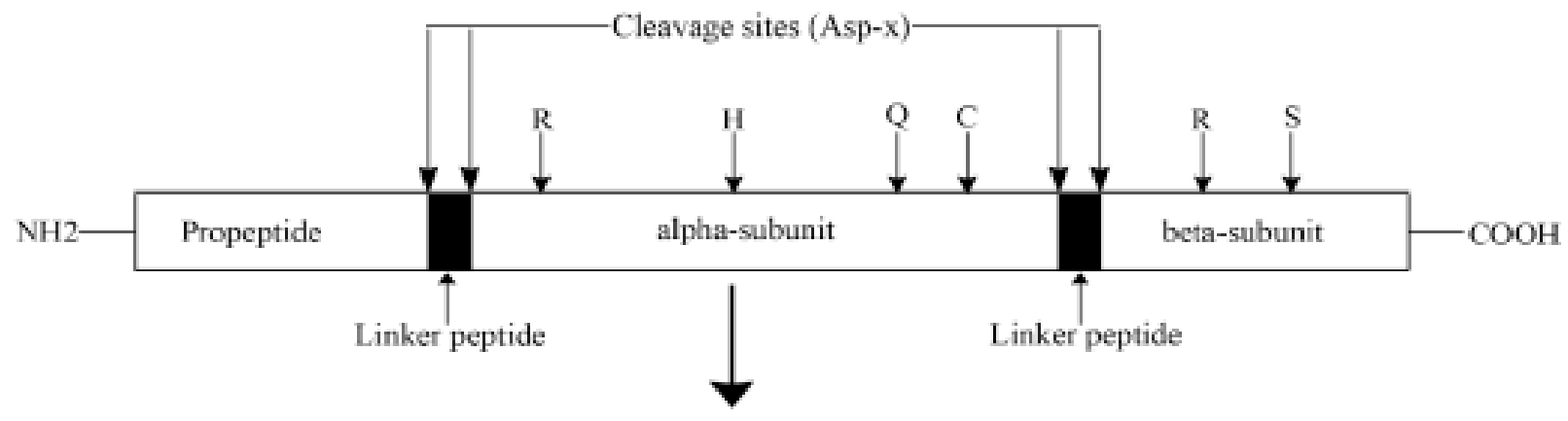

Activation by cleavage
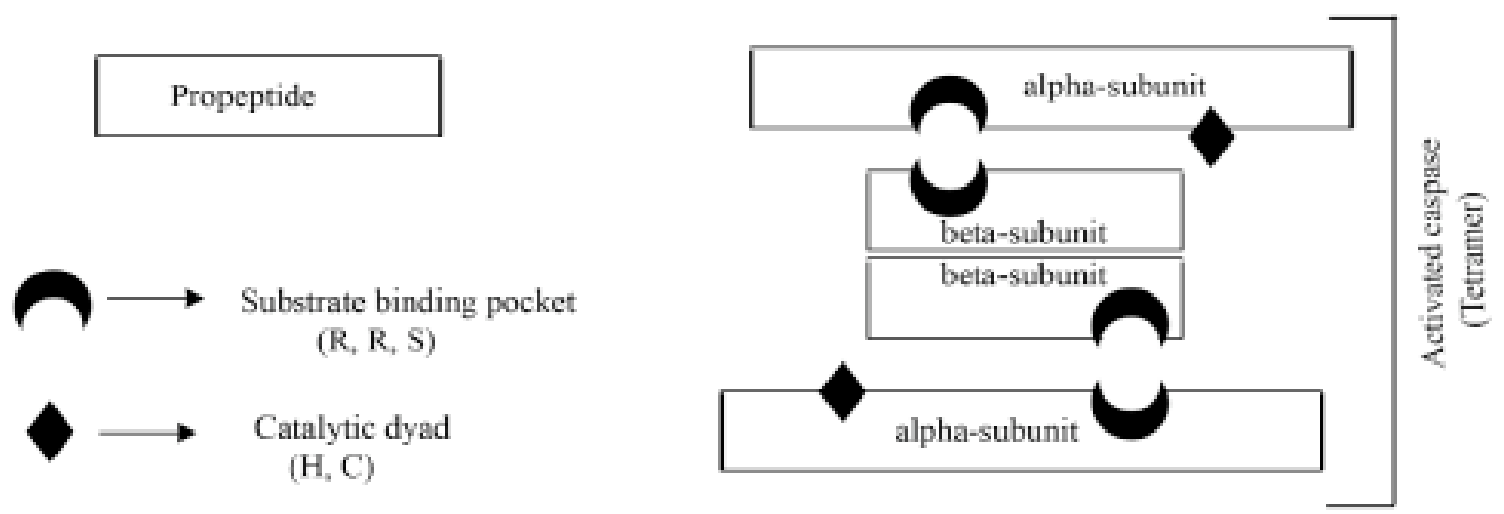

Fig. (1). Diagrammatic representation of the activation of human caspase 1: Caspases are activated by proteolytically removing the propeptide and the linker peptides from the inactive caspase and cleaving the rest of the caspase into larger $\alpha$-subunit and smaller $\beta$-subunit. These subunits assemble into active tetramer containing two active sites (Nicholson, 1999; Grutter, 2000).

from Zea mays and A. thaliana and PARP activity has been identified in few species [99].

Although there have been numerous efforts to identify proteinases that exhibit caspase activities, plant caspases have remained unidentified [100]. Recent work, however, has unraveled this mystery. Vacuolar processing enzyme (VPE) has been shown to be a protease that exhibits caspase1 activity and is essential for virus-induced hypersensitive cell death [35]. Direct evidence has been reported for the involvement of VPEs in plant cell death [35, 101-105]. HaraNishimura and coworkers [35] have used a temperature sensitive N-TMV tobacco plant pathogen system to identify the proteases responsible for caspase like activity. The temperature-sensitive N-TMV (tobacco mosaic virus) tobacco plantpathogen system allows massive cell death to be synchronized. At $30^{\circ} \mathrm{C}$, TMV can systemically infect tobacco plants because induction of cell death and defence gene expression is completely suppressed. Upon shifting the temperature to $23^{\circ} \mathrm{C}$, cell death appears throughout the infected plant. A biotinylated caspase inhibitor (biotin-XVAD-FMK) was used to identify the proteins complexing with this inhibitor. The inhibitor when infiltrated into tobacco leaves before temperature shift, effectively blocked cell death and specifically bound to protein fractions of $40 \mathrm{KDa}$ and $38 \mathrm{KDa}$. Using antibodies against the intermediate and mature forms of VPE these fractions were recognized as two forms of VPE, indicating that the caspase like activity was performed by VPE. Infiltration of leaves with YVAD-CHO as well as specific VPE inhibitor (ESEN-CHO) abolished lesion formation. In addition, in VPE silenced plants hypersensitive cell death response to TMV was greatly suppressed. These results clearly demonstrate the caspase like activity of VPE and its involvement in TMV induced cell death. Cell death is accompanied by an increase in YVADase activity but not by DEVDase activity [106]. This suggests the involvement of VPEs in cell death and shows that VPEs are among the targets of caspase inhibitors in plants. Arabidopsis has four VPE genes ( $\alpha$ VPE, $\beta$ VPE, $\gamma$ VPE, $\delta$ VPE) which are separated into seed type and vegetative type $[76,107]$. VPE is an asparaginyl endopeptidase [108]. It cleaves peptide bonds on the C-terminal side of Asparagine residues exposed on molecular surface of proprotein precursors to generate the respective mature proteins [109-111]. However, it also has been shown that VPE cleaves peptide bonds on the Cterminal side of aspartic acid residues [112]. VPE recognizes aspartic acid when it is part of the YVAD sequence of a caspase-1 substrate, but does not necessarily recognize other aspartic acid residues [35], similar to caspase-1 [113]. VPE, like caspases, is a cysteine protease. Although VPE is not related to the caspase family or the metacaspase family, VPE and caspase-1 share several enzymatic properties (Fig. 2). Two residues of the catalytic dyad in VPE (histidine and cysteine; Fig. 2) [112] are comparable to His237 and Cys285 of the catalytic dyad in human caspase-1 [114]. The QACRG pentapeptide of the active site of caspase- 1 is similar to the $\mathrm{E}(\mathrm{A} / \mathrm{G}) \mathrm{CES}$ pentapeptide of the active site of VPEs. A similar comparison was also done for human caspase- 8 and Arabidopsis $\gamma$ VPE [104]. In addition, each of three essential 

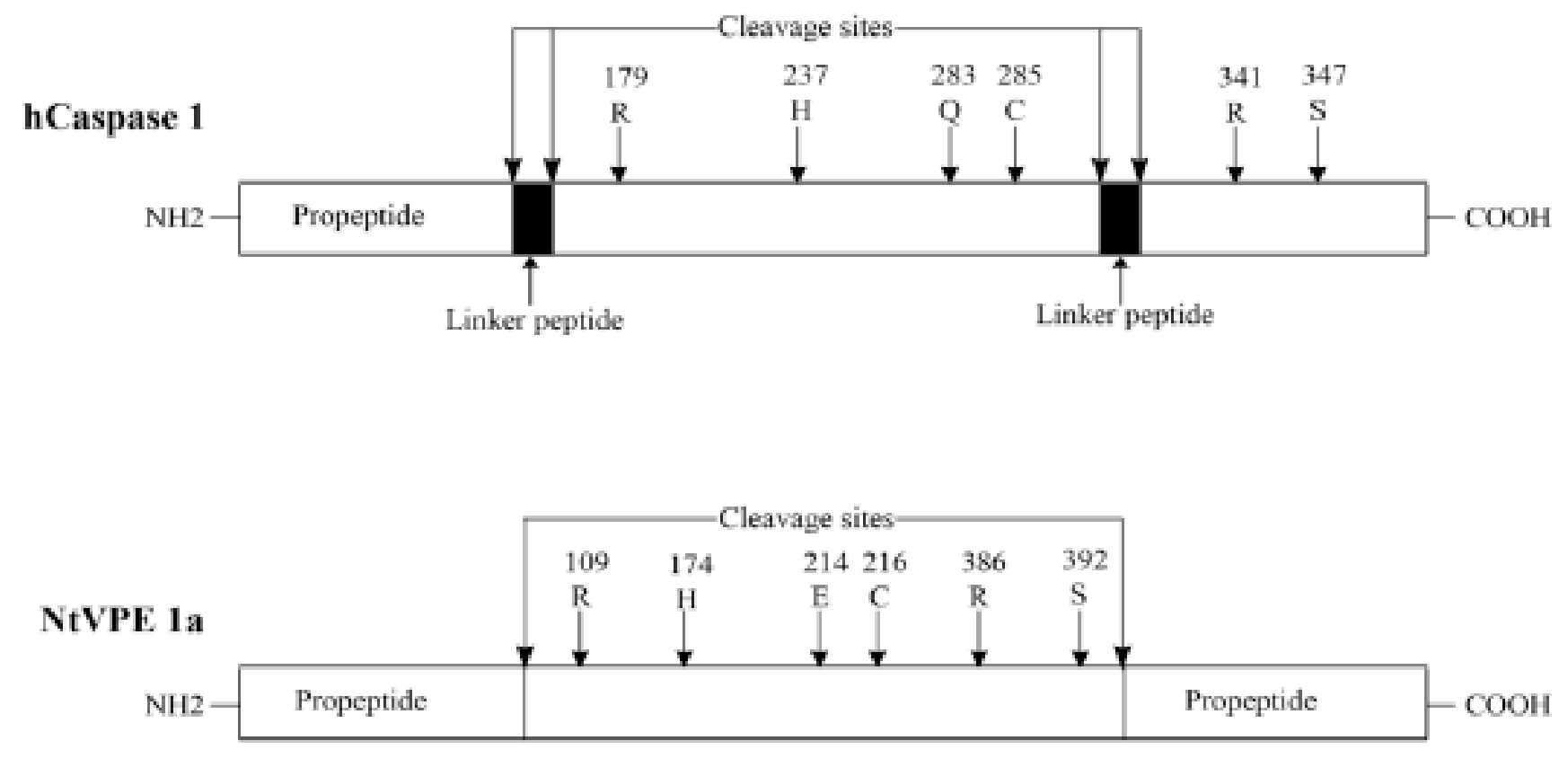

Fig. (2). Schematic representation of active site residues among the human caspase1 (hCaspase1) and Nicotiana tabacum VPE (NtVPE1a). Histidine 237 and Cystein 285 that are involved in catalysis in hcaspase1 correspond to H174 and C216 of NtVPE1a and Argenine 179, Argenine 341, Serine 347 involved in substrate binding in hcaspase1 correspond to R109, R386 and S392 in case of NTVPE1a. Caspase1 and plant VPEs are activated by proteolytically removing the propeptides and the linker peptides from the inactive caspases which is then converted into active caspase.

amino acids, Arg179, Arg341 and Ser347, which form the substrate-binding pocket of caspase-1 [109-111] are conserved in VPEs. This is the case for all of the more than 20 VPEs that are currently in databases. The substrate binding pocket of VPE might be similar to the substrate-binding pocket of caspase-1. Both VPE [114] and caspase-1 [115] are subjected to self-catalytic conversion/activation from their inactive precursors.

With the sequencing of the complete genome of the model plant Arabidopsis thaliana (Arabidopsis Genome Initiative, 2000), these caspase like activities have steered an intensive but frustrating search for caspase genes within plants. At the end of 2000, distant caspase relatives were discovered in silico in plants, the metacaspases that contain some of the structural features that are characteristic of the animal caspases [116-117]. The Arabidopsis thaliana genome contains nine metacaspases. The function(s) and substrate specificity of the metacaspases from plants have not yet been investigated. The increased expression of one of the tomato metacaspases during infection with the necrotrophic pathogen Botrytis cinerea suggests a possible role for plant metacaspases in cell death [118]. The recent findings by Peter Bozhkov and colleagues [119] also indicate that a plant metacaspase might be involved in cell death. These authors studied proteolytic activity during embryogenesis in Norway spruce (Picea abies). Concomitant with massive cell death during shape remodelling, an increase in VEIDase activity (equivalent to activity of human caspase-6) was observed. Treatment with VEIDase inhibitor VEIDfluoromethylketone (VEID-FMK) inhibited cell death and prevented normal embryo development. The authors used a range of other caspase substrates but, apart from IETD- 7amino-4-methylcoumarin, these were cleaved poorly. The VEIDase activity was sensitive to $\mathrm{pH}$, ionic strength and
$\mathrm{Zn}^{2+}$ comparable to human caspase- 6 . The substrate specificity of the Norway spruce VEIDase appears similar to that of the yeast metacaspase YCA1 [120], suggesting that the plant VEIDase involved in cell death is a metacaspase. This group also showed that silencing of a metacaspase gene (EMBL database Accession no. AJ534970) reduced VEIDase activity and cell death, and inhibited embryonic pattern formation [121]. These findings suggested that plant metacaspases were among the targets of the human caspase inhibitors and perhaps metacaspases functionally resemble animal caspases. But later in vitro experiments have shown that $m c I I-P a$ (type II metacaspase gene) had Arg but not Asp specificity [122]. Because knocking down $\mathrm{mcII}-\mathrm{Pa}$ not only disrupted cell death but also blocked embryonic differentiation, it was speculated that mcII-Pa might be primarily involved in cellular differentiation rather than in cell death. Possibly, $\mathrm{mcII}-\mathrm{Pa}$ regulates the actin reorganization observed during cellular differentiation [123], like mammalian caspases do in the cytoskeletal rearrangements during apoptosis [124]. In Arabidopsis, mere constitutive overexpression or disruption of metacaspase genes does not lead to an obvious phenotype $[125,126]$ and, thus, a role for metacaspases in cell death or other processes has not been identified yet. Redundancy may exist between the various members of this family, or additional factors may be necessary to activate ectopically expressed metacaspases.

\section{MAJOR PROTEINS RESPONSIBLE FOR THE ACTI- VATION OF THE EXECUTORS OF PCD: THE ADAPTORS}

The controlled activation of caspase precursors (Zymogens) is achieved by adaptor proteins that bind to them through shared motifs. Tumour Necrosis Factor (TNF) receptors superfamily or apoptogenic cofactors released by the 
mitochondria can be mentioned as examples of adaptors. Caspases- 8 is activated when death effector domains (DEDs) in its pro domain bind to the C-terminal DED in adaptor molecule Fas-associated death domain (FADD); similarly Caspase- 9 is activated after the association of Caspase Recruitment Domain (CARD) in its prodomain with the CARD in another cofactor protein, Apoptosis Protease Activating Factor-1 (APAF-1) [8]. In the worm C. elegans, Ced-4 acts as the adaptor molecule. Database searches have identified several motifs of similarities between Ced-4, APAF-1 and proteins encoded by resistance genes regulating $\mathrm{HR}$ in plants. The conserved domain has been coined as NB-ARC [127].

\section{INTRACELLULAR CONTROLS: THE REGULA- TORS}

A decision to die should not be taken lightly and so it is not surprising that the death programme is regulated in complex ways, both from inside and outside the cell. A major class of intracellular regulators is the B-cell leukemia/lymphoma 2 (Bcl-2) family of proteins, which like caspase family, has been conserved in evolution from Worms to humans [128]. Ced-9 (ced for cell death abnormal) gene in C. elegans encodes such a protein: if it is inactivated, most of the cells in the developing worm die and worm, therefore, dies early in development, but if ced-4 is also inactivated so that apoptosis cannot occur, the worm and all of the cells live [9]. Ced-9 prevents caspase activation by binding to adaptor Ced-4 [8] in the worms. So, it seems that the only reason any cells in the developing worm live is that ced-9 normally keeps the death programme suppressed in these cells. Ced-9 gene is similar to the humans $b c l-2$ gene. Fifteen $b c l-2$ family members have been identified so far in the mammals. Some such as Bcl-2, Bcl-XL, Bcl-W etc. suppress apoptosis (anti apoptotic): others such as BCL2 associated $\mathrm{x}$ protein (Bax), BCL2 antagonist/ killer (Bak), BCL2related ovarian killer (Bok), BCLxL/BCL2 associated death promoter $(\mathrm{Bad})$ and $\mathrm{BH} 3$ interacting domain death agonist (Bid) promote it (proapoptotic) [128]. Some of these proteins can bind to each other: when an apoptosis suppressor forms a complex with an apoptosis promoters, each protein inhibits the others function. The ratio of suppressor to promoters helps determine a cell's susceptibility to apoptosis [129].

It is now an established fact that mitochondria which are called the powerhouses of the cell not only generate energy for cellular activities but also play an important role in cell death [130] in animals. They release several death promoting factors such as cytochrome $\mathrm{C}(\mathrm{Cyt}-\mathrm{C})$ (which contribute to caspase activation), Apaf-1, Apoptosis inducing Factor (AIF), procaspase-3, $\mathrm{Ca}^{2+}$ and reactive oxygen species (ROS) in response to various stimuli. Different mechanisms have been suggested to explain the release of apoptogenic factors from mitochondria, induced by proapoptotic proteins $[131,132]$. The first involves Bax that could simply oligomerise in outer mitochondrial membrane (OMM) to form a channel. Alternatively, Bax, in association with either the voltage-dependent anion channel (VDAC) or truncated Bid (tBid), could promote the formation of pores allowing the passage of soluble proteins. Alternative models have been suggested in which, during early stages of apoptosis, the inner mitochondrial membrane (IMM) plays a key role. The first one implies that water and solutes enter the mitochondrial matrix, inducing swelling of mitochondria [131, 132]. This process is mediated by either VDAC or the opening of a permeability transition pore (PTP) [133]. The PTP may be defined as a voltage-dependent, cyclosporin A (CsA)sensitive, high conductance inner membrane channel. The molecular structure of PTP is still unknown, although evidence suggests that it may be formed of several components, including matrix cyclophilin $\mathrm{D}$, the outer membrane VDAC, the innermembrane adenine nucleotide translocase (ANT), peripheral benzodiazepin receptor and $\mathrm{Bcl}-2$, hexokinase bound to VDAC, and intermembrane creatine kinase [134] evidence indicates that the mitochondria-associated hexokinase plays an important role in the control of apoptosis in mammals $[135,136]$. Hexokinase is an integral component of the PTP through its interaction with porin or the voltage-dependent anion channel (VDAC), and hexokinase binding to the VDAC interferes with the opening of the PTP, thereby inhibiting cytochrome c release and apoptosis [137]. Thus, detachment of hexokinase from the mitochondria potentiates, and its overexpression inhibits mitochondrial dysfunction and cell death induced by various stimuli. Recent studies have shown that cyclophilin D, another component of the PTP, is a key factor in the regulation of PTP function and that cyclophilin D-dependent mitochondrial permeability transitions are required to mediate some forms of necrotic cell death but not apoptotic cell death [138]. However, these observations do not exclude the possibility that certain forms of apoptosis are mediated by the mitochondrial permeability transitions, because some forms of apoptosis are significantly inhibited by cyclosporin A, a specific inhibitor of cyclophilin activity [139]. The pore open-closed transitions are highly regulated by multiple effectors at discrete sites. Factors affecting PTP can be subdivided into matrix and membrane effectors. The former include both openers $\left(\mathrm{Ca}^{2+}\right.$, phosphate, oxidizing agents, ${ }^{-} \mathrm{OH}$ and atractylate) and inhibitors $\left[\right.$ CyclosporinA(CsA), Adenosine diphospate $\mathrm{H}^{+}$, bongkrekate and reducing agents]. Among the latter, a high (inside-negative) membrane potential tends to stabilize the PTP in a closed conformation, whereas depolarisation by different uncouplers determines its aperture. PTP is also regulated by quinones, which prevent $\mathrm{Ca}^{2+}$-dependent pore opening. The Bcl-2 proteins are membrane spanning and have at least one of the four Bcl-2 homology $(\mathrm{BH})$ domains. It is shown that the proapoptotic Bax interacts with VDAC and ANT, and brings about a conformational alteration to form a megachannel leading to the release of Cyt-C [131]. The pore conductance of VDAC has been shown to increase in the presence of Bax in artificial membranes and this increase is blocked by Bcl-XL. Bax and Bim interact with VDAC and lead to the release of Cyt-C, whereas Bcl-XL blocks this release [140]. The permeabilization of the IMM to solutes with molecular mass up to $1.5 \mathrm{kDa}$, caused by the aperture of the PTP results in the complete dissipation of mitochondrial electrical potential. Consequently, the high concentration of solutes present in the matrix induces an osmotic swelling that could ultimately lead to OMM rupture and the consequent release of proteins from the intermembrane mitochondrial space (IMS) [132].

A further model refers to the non-swelling mechanism involving the OMM. In this mechanism a crucial role is performed by VDAC, which interacts with Bax, forming a pore 
through which Cyt-C is released [141]. The first evidence derives from a study in which the overexpression of mammalian Bax gene in tobacco plants causes hypersensitive-like lesions and induces defence genes [142]. Recent experimental findings seem to corroborate this mechanism, suggesting that VDAC can play a crucial role in PCD pathway being a conserved element in both plants and animals. In agreement, VDAC expression increases during HR, senescence and heat-induced PCD in A. thaliana cells [142]. This evidence indicates a putative dual role for VDAC, as a component of PTP or as a channel that interacts with Bax.

In animal cells, the significance of the release of Cyt-C is the subsequent assembly of the apoptosome complex that is followed by the activation of the executioner caspases. A1though evidences are lacking for the formation of apoptosome in plant cells, sequence alignments have revealed significant similarities among regions of $C$. elegans cell death gene that encodes a protease activating factor (Ced-4), human Apaf-1 and several plant resistance genes. Although these resistance genes do not contain CARD but may be assumed to function as controlling adaptors in plant protein complexes which are activated during HR [143]. Thus, the subsequent fate of $\mathrm{Cyt}-\mathrm{C}$ is still problematic, because the formation of the complex like the apoptosome, is largely speculative. If an apoptosome- like complex exists in plants, it may interact with caspase-like proteases (Metacaspases, VPE) by analogy with the system in animal cells. In addition, a further evidence supporting the mitochondrial involvement in plant PCD is provided by the reports of strong increase in HSP during harpin HR in A. thaliana cells [144]. HSPs are considered to partially suppress apoptosis in animal cells, by preventing Cyt-C release and disrupting the apoptosome. Plant HSPs are considered to accomplish comparable effects [145].

The fundamental features of PCD are believed to be conserved throughout metazoans and plants Fig. (3), [34]. In support of this, a study carried out on tobacco shows that the expression of Bax, which is a mammalian pro-apoptotic protein, triggered cell death in tobacco leaf [146, 147]. Moreover, overproduction of animal cell death suppressors Bcl-XL and Ced-9 conferred enhanced resistance to UV-b and paraquat treatment and salt, cold and wound stresses in tobacco plants Fig. (3), [148]. However, recent research demonstrated that homologous plant genes for cell death suppressors such as $b c l-2, B c l-X L$ from humans \& ced-9 from $C$. elegans are not found in Arabidopsis genome whose sequence has been presented as the first complete genomic sequence of higher plants [141]. Recently, it has been reported that a gene encoding a homolog of Bax inhibitor (BI1) from Arabidopsis inhibits mammalian Bax action in planta [149]. This is the first report on the direct contribution to plant cell death of a plant originating gene that is a homolog of animal cell death related gene. An Arabidopsis homolog AtBI-1(Arabidopsis Bax inhibitor 1) was identified from the genome sequencing project. The identity level is $37.5 \%$ AtBI-1 shares $41 \%$ amino acid identity with mammalian BI-1(mBI-1). Plant homologs of BI-1 gene for several plant species including Oryza sativa (OsBI-1), Arabidopsis thaliana (AtBI-1) have been cloned and characterized to various extents [150-153]. Intriguingly enough, however, when AtBI-1 was transfected into the mammalian cell sys- tems, it did not suppress Bax induced cell death in the human cells. Infact, AtBI-1 induced cell death comparable to Bax [154]. The possibility exists that AtBI-1 might directly damage the mitochondrial structure causing $\mathrm{Cyt}-\mathrm{C}$ release. However, co-transfection of the cells with both human BI-1 and AtBI-1 crippled cell death, suggesting preferably a dominant-negative mechanism in which AtBI-1 induced apoptosis is minimized by overexpressed mBI-1 [154]. It may, thus, be speculated that AtBI-1 competitively interacts with endogenous $\mathrm{mBI}-1$ or BI-1 target protein, interfering with its function and thereby triggering cell death. In this regard, in vitro binding of BI-1 with Bcl-2 but not with Bax has been demonstrated [155]. Thus, it remains unclear how BI-1 suppresses Bax's function given that yeast and plants contain no obvious Bcl-2 homologs [141]. Interestingly, downregulation of a tobacco BI-1 homolog using an antisense RNA approach resulted in accelerated cell death of tobacco BY-cells upon carbon starvation [150]. Downregulation of rice BI-1 in cultured rice cells upon challenge with a fungal elicitor from Megnaporthe grisea was concomitant with the progression of cell death and, conversely, overexpressed rice BI-1 can improve cell survival against the elicitor [156]. Another study found that decreased BI-1 expression correlated with chemical-induced resistance of barley to the infection of a biotrophic fungal pathogen powdery mildew (Blumeria graminis), and overexpression of barley BI-1 at a single-cell level induces hyper susceptibility and could reverse the fungal resistance that is conferred by the loss of MLO, a negative regulator of cell death and defense response in barley [157]. Although these observations support the idea that BI-1 homologs of yeast and plants have an anti-PCD function, the physiological importance of BI-1 and the impact of its loss of function in plants are still unclear at the whole plant level as clear genetic evidence is absent. However, a study carried out more recently [158] identified and characterized two independent Arabidopsis mutants with T-DNA insersion in the AtBI-1 gene. The phenotype of atbi1-1 and atbi1-2, with a C-terminal missense mutation and a gene knockout, respectively, is indistinguishable from wild-type plants under normal growth conditions. However, these two mutants exhibit accelerated progression of cell death upon infiltration of leaf tissues with a PCD-inducing fungal toxin fumonisin B1 (FB1) and increased sensitivity to heat shock-induced cell death. Under these conditions, expression of AtBI1 mRNA has been shown to be upregulated in wild-type leaves prior to the activation of cell death, suggesting that increase of AtBI1 expression is important for basal suppression of cell death progression. Over-expression of AtBI-1 transgene in the two homozygous mutant backgrounds rescued the accelerated cell death phenotypes. Together, these results provide direct genetic evidence for a role of BI-1 as an attenuator for cell death progression triggered by both biotic and abiotic types of cell death signals in Arabidopsis.

\section{CONCLUDING REMARKS}

Conclusively, there are likely to be inherent differences in the operational mechanism of PCD between plants and animals; there is also the possibility for the involvement of different operational mechanisms of PCD in different plant cell types, i.e. more than one pathway of PCD is likely to be operative in plants, while in animals there seems to be only one programme (Fig. 3). No plant system is yet described 


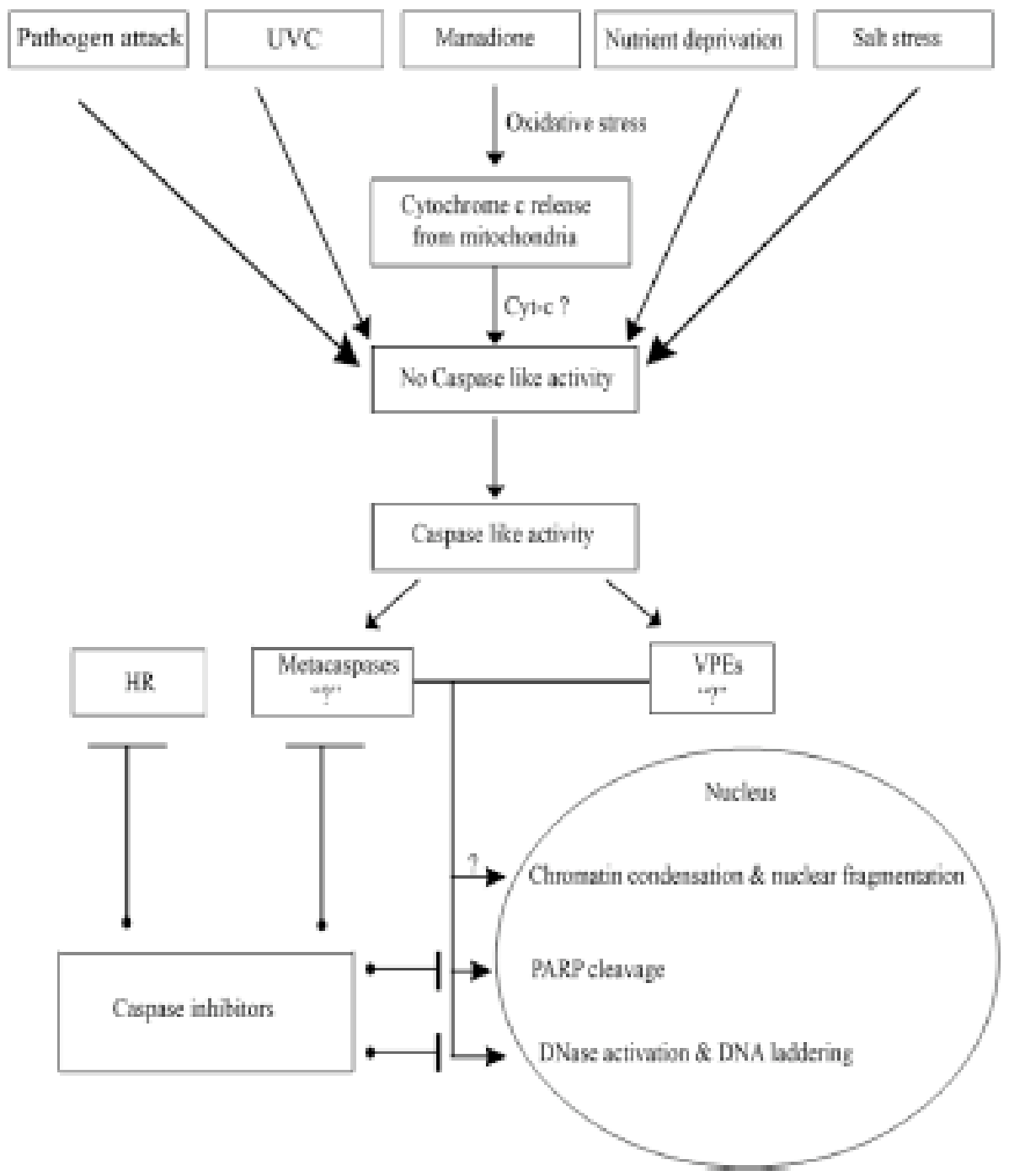

Fig. (3). Chosen examples of treatments triggering different animal or plant PCD hallmarks in plant cell. ? Indicates events that have been shown in animals and have not been detected in plants and "?" Indicates arbitrary functional assignment in plants.

which shows all features common to animal PCD. The comparison of plant PCD and apoptosis in animals show important differences regarding morphological changes occurring in the dying cells and enzymes involved in the process (Fig. 3). However, the final execution of the process, DNA fragmentation and nuclear disorganization, has similarities in animal and plant cells, suggesting that it might have evolved from a common ancestor. VPEs and metacaspases appear to be the prime candidates that seem to be responsible for the caspase like activities observed. However, until now, the role of metacaspases in cell death still remained enigmatic, and both up- and down-regulation of metacaspases have yielded conflicting data. However, such approaches bear the risk that a constitutive perturbation of genes that are essential for normal cellular homeostasis leads to over interpretation. A1ternative routes toward unraveling the function of metacaspases could involve the identification of their substrates by using technologies that allow direct characterization of in vivo protein processing on a proteome-wide scale [159]. Knowing the degradome specificity of metacaspases could reveal their role in cellular and developmental processes, including cell death. Overproduction of the cleavage fragments and/or of uncleavable mutant proteins would help elu- cidate the functional consequences of substrate cleavage by metacaspases. The many intriguing similarities with PCD in animals will need to be rigorously tested to demonstrate that they are conserved, and are derived from a common ancestral origin.

Despite the fact that there is a significant progress in our understanding of plant PCD in recent years, its exact control mechanism is still obscure. Deployment of reverse genetic approaches such as PTGS/RNAi strategies and knockout screens using T-DNA or transposon insertion collections, coupled with global expression approaches such as microarray analysis should help speed up the first essential step of identifying the important players involved in plant cell death activation. Research works along these approaches throw light onto new insights and mechanisms involved in genetic manipulations, revealing new regulator(s) that may be highly rewarding.

\section{ACKNOWLEDGEMENTS}

The present studies could be as a consequence of collaborations among (i) CET, IFTM, Moradabad, UP, India; (ii) IVRI, Izatnagar, UP, India; (iii) Halberg Hospital and Re- 
search Institute, Moradabad, UP, India. An institutional research promotion grant to the Department of Biotechnology, College of Engineering and Technology, Moradabad, U.P., India is acknowledged. The authors are grateful to Prof. R. M. Dubey (Managing Director, CET, IFTM, Moradabad, U.P, India) for providing the necessary facilities and encouragement. The authors are also thankful to Prof. A. Srivastav (Director), Prof. B.N. Basu (Dean, Academics), Prof. B.N. Kaul (Dean, Administration), College of Engineering and Technology, Moradabad, U.P., India, for their generous help and suggestions during the course of work.

\section{REFERENCES}

[1] Wertz IE, Hanley MR. Diverse molecular provocation of programmed cell death. Trends Biochem Sci 1996; 21: 359-64.

[2] Mishra S, Somnath PR, Huang Z, Vijayaraghavan S. Binding and inactivation of the germ cell-specific protein phosphatase PP1gamma 2 by sds 22 during epididymal sperm maturation. Biol Reprod 2003; 69: 1572-79.

[3] Sharma V, Kalim S, Srivastava MK, et al. Oxidative stress coxsakievirus infections as mediators of beta cell damage: A review. Sci Res Essay 2009; 4: 42-58.

[4] Nanda S, Varshney VP, Chauhan N, et al. Synergistic cytotoxic effect of Syzygium aromaticum extract and gemicitabine on human cervical cancer cell line. J Adv Res Biol Sci 2009a; In Press.

[5] Nanda S, Varshney VP, Mishra S. Biochemical characterization of mechanism of binding of sds 22 to the spermatozoa- specific protein phosphatase in Swiss Albino rat. J Appl Biosci 2009b; In Press.

[6] Ameisen JC. On the origin, evolution and nature of programmed cell death: a timeline of four billion years. Cell Death Differ 2002; 9: 367-93

[7] Gray J. Paradigms of the evolution of programmed cell death. In Gray J, Ed. Programmed Cell Death in Plants, Boca Raton CRC Press: 2004; pp. 1-25.

[8] Vaux DL, Korsmeyer SJ. Cell death in development. Cell 1999; 96: 245-54.

[9] Kerr JFR, Wyllie AH, Currie AR. Apoptosis: A basic biological phenomenon with wide-ranging implications in tissue kinetics. $\mathrm{Br} \mathrm{J}$ Cancer 1972; 26: 239-57.

[10] Earnshaw WC. Nuclear changes in apoptosis. Curr Opin Cell Biol 1995; 7: 337- 43.

[11] O'Brien IEW, Baguley BC, Murray BG, et al. Early stages of the apoptotic pathway in plant cells are reversible. Plant J 1998; 13: 803-14.

[12] Mishra S, Dwivedi SP, Dwivedi N, Singh RB. Immune response and possible causes of $\mathrm{CD}^{+} \mathrm{T}$-cell depletion in human immunodeficiency virus (HIV)-1 infection. Open Nutra J 2009a; 2: 46-51.

[13] Mishra S, Singh RB, Dwivedi SP, et al. Effects of Nutraceuticals on genetic expressions. Open Nutra J 2009b; 2: 70-80.

[14] Wyllie AH. Glucocorticoid-induced thymocyte apoptosis associated with endogenous endonuclease activation. Nature 1980; 284: $555-6$.

[15] Wang H, Li J, Bostock RM, Gilchrist DG. The apoptosis: a functional paradigm for programmed plant cell death induced by a hostselective phytotoxin and invoked during development. Plant Cell 1996a; 8: 375-91.

[16] McCabe PF, Levine A, Meijer PJ, et al. A programmed cell death pathway activated in carrot cells cultured at low cell density. Plant J 1997; 12: 267-80.

[17] Fath A, Bethke PC, Jones RL. Barley aleurone cell death is not apoptotic: characterization of nuclease activities and DNA degradation. Plant J 1999; 20: 305-15

[18] Henkel R, Hajimohammad M, Stalf T, et al. Influence of deoxyribonucleic acid damageon fertilization and pregnancy. Fertil Steril 2004; 81: 965-72.

[19] Seli E, Gardner DK, Schoolcraft WB, et al. Extent of nuclear DNA damage in ejaculated spermatozoa impacts on blastocyst development after in vitro fertilization. Fertil Steril 2004; 82: 378-83.

[20] Sharma RK, Said T, Agarwal A. Sperm DNA damage and its clinical relevance in assessing reproductive outcome. Asian J Androl 2004; 6: 139-48.
[21] Spano M, Seli E, Bizzaro D, et al. The significance of sperm nuclear DNA strand breaks on reproductive outcome. Curr Opin Obstet Gynecol 2005; 17: 255-60.

[22] Erenpreiss J, Spano M, Erenpreisa J, et al. A sperm chromatin structure and male fertility: biological and clinical aspects. Asian J Androl 2006; 8: 11-29.

[23] Agarwal A, Said TM. Oxidative stress, DNA damage apoptosis in male infertility: a clinical approach. Br J Urol Int 2003; 95: 50307.

[24] Sakkas D, Moffat t O, Manicardi GC, et al. Nature of DNA damage in ejaculated human spermatozoa and the possible involvement of apoptosis. Biol Reprod 2002; 66: 1061-7.

[25] Lewis SEM, Aitken RJ. DNA damage to spermatozoa has impacts on fertilization and pregnancy. Cell Tissue Res 2005; 322: 33-41.

[26] Martinez F, Rienzi L, Iacobelli M, et al. Caspase activity in preimplantation human embryos is not associated with apoptosis. Hum Reprod 2002; 17: 1584-90.

[27] Shafik A, Shafik AA, Shafik I, El Sibai O. Sperm DNA fragmentation. Arch Androl 2006; 52: 197-208.

[28] Tesarik J, Mendoza-Tesarik R, Mendoza C. Sperm nuclear DNA damage: update on the mechanism, diagnosis and treatment. Reprod Biomed Online 2006; 12: 715-21.

[29] Mishra S, Sangwan RS. Dynamics of tropane alkaloids in Duboisia myoporoides leaf during development. J Herbs Spices Med Plants 1996; 4: 61-70.

[30] Mishra S, Sangwan RS. Changes in fatty acid composition of polar lipids associated with growth and senescence in leaves of $\mathrm{Ca}$ tharanthus roseus. Afr J Plant Sci 2008; 2: 34-7.

[31] Mishra S, Sanwal GG. Effect of Cuscuta infection on chloroplast lipid composition of Brassica leaves. Eur J Plant Pathol 1994; 100:61-70.

[32] Mishra S, Shanker S, Sangwan RS. Lipid profile in relation to tropane alkaloid production and accumulation during leaf growth and senescence in Duboisia myoporoides. Fitoterapia 1998; 69: 72.

[33] Mishra S, Tyagi A, Singh IV, Sangwan RS. Changes in lipid profile during growth and senescence of Catharanthus roseus leaf. Braz J Plant Physiol 2006; 18: 447.

[34] Pennel RI, Lamb C. Programmed cell death in plants. Plant Cell 1997; 9: 1157-68.

[35] Hatsugai N, Kuroyanagi M, Yamada K, et al. A plant vacuolar protease, VPE, mediates virus-induced hypersensitive cell death. Science 2004; 305: 855-58.

[36] Heath MC. Hypersensitive response-related death. Plant Mol Biol 2000; 44: 321-34.

[37] Danon A, Gallois P. UV C radiation induces apoptotic like changes in Arabidopsis thaliana. FEBS Lett 1998; 437: 131-6.

[38] Peitsch MC, Polzar B, Stepham H, et al. Characterization of the endogenous deoxyribonuclease involved in nuclear DNA degradation during apotosis (Programmed cell death). EMBO J 1993; 12: 371-7.

[39] Enari M, Sakahira H, Yokoyama H, et al. A caspase-activated DNase that degrades DNA during apoptosis. Nature 1998; 391: 4350 .

[40] Halenbeck R, MacDonald H, Roulston A, et al. CPAN, a human nuclease regulated by the caspase-sensitive inhibitor DFF45. Curr Biol 1998; 23: 537-40.

[41] Liu X, Li P, Widlak P, et al. The 40-kDasubunit of DNA fragmentation factor induces DNA fragmentation and chromatin condensation during apoptosis. Proc Natl Acad Sci USA 1998; 95: 8461-6.

[42] Cohen JJ. Apoptosis. Immunol Today 1993; 14: 126-30.

[43] D'Silva I, Poirier GG, Heath MC. Activation of cysteine proteases in cowpea plants during the hypersensitive response: a form of programmed cell death. Exp Cell Res 1998; 245: 389-99.

[44] Danon A, Rotari VI, Gordon A, et al. Ultraviolet-C overexposure induces programmed cell death in Arabidopsis, which is mediated by Caspase-like activities and which can be suppressed by caspase inhibitors, p35 and defender against apoptotic death. J Biol Chem 2004; 279: 779-87.

[45] White E. Life, death, and the pursuit of apoptosis. Genes Dev 1996; 10: 1-15.

[46] Miller LJ, Marx J. Apoptosis. Science 1998; 281: 1301.

[47] Hengartner MO. Apoptosis: Death by crowd control. Science 1998; 281: 1298-9.

[48] Chinnaiyan AM, Dixit VM. The cell-death machine. Curr Biol 1996; 6: 555-62. 
[49] Wang M, Oppedijk BJ, Lu X, et al. Apoptosis in barley aleurone during germination and its inhibition by abscisic acid. Plant Mol Biol 1996b; 32: 1125-34.

[50] Orzaez D, Granell A. DNA fragmentation is regulated by ethylene during carpel senescence in Pisum sativum. Plant J 1997a; 11: 13744.

[51] Young TE, Gallie DR, Demason DA. Ethylene mediated programmed cell death during maize endosperm development of wildtype and shrunken2 genotypes. Plant Physiol 1997; 115: 737-51.

[52] Orzaez D, Granell A. The plant homologue of the defender against apoptotic death gene is down-regulated during senescence of flower petals. FEBS Lett 1997b; 404: 275-8.

[53] Yen $\mathrm{CH}$, Yang $\mathrm{CH}$. Evidence for programmed cell death during leaf senescence in plants. Plant Cell Physiol 1998; 39: 922-7.

[54] Wang M, Hoekstra S, van Bergen S, et al. Apoptosis in developing anthers and the role of $\mathrm{ABA}$ in this process during androgenesis in Hordeum vulgare L. Plant Mol Biol 1999; 39: 489-501.

[55] Koukalova B, Kovarik A, Fajkus J, Siroky J. Chromatin fragmentation associated with apoptotic changes in tobacco cells exposed to cold stress. FEBS Lett 1997; 414: 289-92.

[56] Callard D, Axelos M, Mazzolini L. Novel marker for late phases of the growth cycle of Arabidopsis thaliana cell-suspension cultures are expressed during organ senescence. Plant Physiol 1996; 112: $705-15$.

[57] Katsuhara M. Apoptosis-like cell death in barley roots under salt stress. Plant Cell Physiol 1997; 38: 1091-3.

[58] Stein JC, Hansen G. Mannose induces an endonuclease responsible for DNA laddering in plant cells. Plant Physiol 1999; 121: 71-9.

[59] Ryerson DE, Heath MC. Cleavage of nuclear DNA into oligonucleosomal fragments during cell death induced by fungal infection or by abiotic treatments. Plant Cell 1996; 8: 393-402.

[60] Navarre DA, Wolpert TJ. Victorin induction of an apoptotic/ senescence-like responses in oats. Plant Cell 1999; 11: 237-49.

[61] Mittler R, Lam E. Characterization of nuclease activities and DNA fragmentation induced upon hypersensitive response cell death and mechanical stress. Plant Mol Biol 1997; 34: 209-21.

[62] Pandey S, Walker PR, Sikorska M. Separate pools of endonuclease activity are responsible for internucleosomal and high molecular mass DNA fragmentation during apoptosis. Biochem. Cell Biol 1994; 72: 625-9.

[63] Oberhammer F, Wilson JW, Dive C, et al. Apoptotic death in epithelial cells: Cleavage of DNA to 300 and or $50 \mathrm{~kb}$ fragments prior to or in the absence of internucleosomal fragmentation. EMBO J 1993; 12: 3679-84.

[64] Sugiyama M, Ito J, Aoyagi S, Fukuda H. Endonucleases. Plant Mol Biol 2004; 44: 387-97.

[65] Tada Y, Hata S, Takata Y, et al. Induction and signaling of an apoptotic typified by DNA laddering in the defence response of response oats to infection and elicitors. Mol Plant Microbe Interact 2001; 14: 477-86.

[66] Kusaka K, Tada Y, Shigemi T, et al. Coordinate involvement of cysteine protease and nuclease in the executive phase of plant apoptosis. FEBS Lett 2004; 578: 363-7.

[67] Ito J, Fukuda H. ZEN1 is a key enzyme in the degradation of nuclear DNA during programmed cell death of tracheary elements. Plant Cell 2002; 14: 3201-11.

[68] Obara K, Kuriyama H, Fukuda H. Direct evidence of active and rapid nuclear degradation triggered by vacuole rupture during programmed cell death in Zinnia. Plant Physiol 2001; 125: 61526.

[69] Young TE, Gallie DR. Regulation of programmed cell death in maize endosperm by abscisic acid. Plant Mol Biol 2000; 42: 397414.

[70] Dom'inguez F, Moreno J, Cejudo FJ. The nucellus degenerates by a process of programmed cell death during the early stages of wheat grain development. Planta 2001; 231: 352-60.

[71] Dom'inguez F, Moreno J, Cejudo FJ. A gibberellin-induced nuclease is localized in the nucleus of wheat aleurone cells undergoing programmed cell death. J Biol Chem 2004; 279: 11530-6.

[72] Domi'nguez F, Cejudo FJ. Identification of a nuclear-localized nuclease from wheat cells undergoing programmed cell death that is able to trigger DNA fragmentation and apoptotic morphology on nuclei from human cells. Biochem J 2006; 397: 529-36.

[73] Samejima K, Earnshaw WC. Trashing the genome: the role of nucleases during apoptosis. Nat Rev Mol Cell Biol 2005; 6: 67788.
[74] Jones AM. Does the plant mitochondrion integrate cellular stress and regulate programmed cell death? Trends Plant Sci 2000; 5: 225-30.

[75] Filonova LH, Bozhkov PV, Brukhin VB, et al. Two waves of programmed cell death occur during formation and development of somatic embryos in the gymnosperm, Norway spruce. J Cell Sci 2000; 113: 4399-411.

[76] Yamada K, Shimada T, Nishimura M, Hara-Nishimura I. A VPEfamily supporting various vacuolar functions in plants. Physiol Plant 2005; 123: S369-75.

[77] Schussler EE, Longstreth DL. Changes in cell structure during the formation of root aerenchyma in Sagittaria lancifolia (Alismataceae). Am J Bot 2000; 87: 12-9.

[78] Delorme VGR, McCabe PF, Kim DJ, Leaver CJ. A matrix metalloproteinase gene is expressed at the boundary of senescence and programmed cell death in cucumber. Plant Physiol 2000; 123: 91727.

[79] Xu Y, Hanson MR. Programmed cell death during pollinationinduced petal senescence in petunia. Plant Physiol 2000; 122: 1323-33.

[80] De Jong AJ, Hoeberichts FA, Yakimova ET, et al. Chemicalinduced apoptotic cell death in tomato cells: Involvement of caspase-like proteases. Planta 2000; 211: 656-62.

[81] Jordan ND, Franklin FCH, Franklin-Tong VE. Evidence for DNA fragmentation triggered in the self-incompatibility response in pollen of Papaver rhoeas. Plant J 2000; 23: 471-9.

[82] Ellis RE, Yuan JY, Horvitz HR. Mechanisms and functions of cell death. Annu Rev Cell Biol 1991; 7: 663-98.

[83] White K, Grether ME, Abrams JM, et al. Genetic control of programmed cell death in Drosophila. Science 1994; 264: 67783.

[84] Kuida, K, Zheng TS, Na SQ, et al. Decreased apoptosis in the brain and premature lethality in CPP32-deficient mice. Nature 1996; 384 : 368-72.

[85] Yuan JY, Shaham S, Ledoux S, et al. The C. elegans cell death gene ced-3 encodes a protein similar to mammalian interleukin-1 $\beta$ converting enzyme. Cell 1993; 75: 641-52.

[86] Nicholson DW. Caspase structure, proteolytic substrates, and function during apoptotic cell death. Cell Death Differ 1999; 6: 102842.

[87] Rudel T. Caspase inhibitors in prevention of apoptosis. Herz 1999; 24: $236-41$.

[88] Thornberry NA, Lazebnik Y. Caspases enemies within. Science 1998; 281: 1312-6.

[89] Garcia-Calvo M, Peterson EP, Leiting B, et al. Inhibition of human caspase by peptide-based and macromolecular inhibitors. J Biol Chem 1998; 273: 32608-13.

[90] de Murcia G, Ménissier de Murcia J. Poly (ADPribose) polymerase: A molecular nick-sensor. Trends Biochem Sci 1994; 19: 1726.

[91] Kumar S. Caspase function in programmed cell death. Cell Death Differ 2007; 14: 32-43.

[92] Timmer JC, Salvesen GS. Caspase substrates. Cell Death Differ 2007; 14: 66-72.

[93] Lazebnik YA, Kaufmann SH, Desnoyers S, et al. Cleavage of poly (ADPribose) polymerase by a proteinase with properties like ICE. Nature 1994; 371: 346-7.

[94] del Pozo O, Lam E. Caspase and programmed cell death in the hypersensitive response of plants to pathogens. Curr Biol 1998; 8: 1129-32.

[95] Lincoln JE, Richael C, Overduin B, et al. 2002 Expression of the antiapoptotic baculovirus p35 gene in tomato blocks programmed cell death and provides broad-spectrum resistance to disease. Proc Natl Acad Sci USA 1998; 99: 15217-21.

[96] del Pozo O, Lam E. Expression of the baculovirus p35 protein in tobacco affects cell death progression and compromises $\mathrm{N}$ gene mediated disease resistance response to tobacco mosaic virus. Mol Plant-Microbe Interact 2003; 16: 485-94.

[97] Sun YL, Zhao Y, Hong X, Zhai ZH. Cytochrome c release and caspase activation during menadione induced apoptosis in plants. FEBS Lett 1999; 462: 317-21.

[98] Tian R-H, Zhang G-Y, Yan C-H, Dai Y-R. Involvement of poly (ADP-ribose) polymerase and activation of caspase-3-like protease in heat shock-induced apoptosis in tobacco suspension cells. FEBS Lett $2000 ; 474: 11-5$. 
[99] O'Farrell M. ADP-ribosylation reactions in plants. Biochimie 1995; 77: 486-91.

[100] Woltering EJ, van der Bent A, Hoeberichts FA. Do plant caspases exist? Plant Physiol 2002; 130: 1764-69.

[101] Lam E. Vacuolar proteases livening up programmed cell death. Trends Cell Biol 2005; 15: 124-7.

[102] Hara-Nishimura I, Hatsugai N, Nakaune S, et al. Vacuolar processing enzyme: An executor of cell death. Curr Opin Plant Biol 2005; 8: 404-8.

[103] Kuroyanagi M, Yamada K, Hatsugai N, et al. Vacuolar processing enzyme is essential for mycotoxin induced cell death in Arabidopsis thaliana. J Biol Chem 2005; 280: 32914-20.

[104] Sanmartin M, Jaroszewski L, Raikhel NV, Rojo E. Caspases. Regulating death since the origin of life. Plant Physiol 2005; 137: 841-7.

[105] Hatsugai N, Kuroyanagi M, Nishimura M, Hara-Nishimura I. A cellular suicide strategy of plants: vacuole-mediated cell death. Apoptosis 2006; 11: 905-11.

[106] Lam E, Del Poza O. Caspase-like protease involvement in the control of plant cell death. Plant Mol Biol 2000; 44: 417-28.

[107] Nakaune S, Yamada K, Kondo M, et al. A novel-type VPE, dVPE, is involved in seed coat formation at the early stage of seed development. Plant Cell 2005; 17: 876-87.

[108] Hara-Nishimura I. Asparaginyl endopeptidase. In Barrett AJ, Rawlings ND, Woessner JF, Eds. Handbook of Proteolytic Enzymes. Academic Press 2003; pp. 846-49.

[109] Hara-Nishimura I, Nishimura M. Proglobulin processing enzyme in vacuoles isolated from developing pumpkin cotyledons. Plant Physiol 1987; 85: 440-5.

[110] Hara-Nishimura I, Inoue K, Nishimura M. A unique vacuolar processing enzyme responsible for conversion of several proprotein precursors into the mature forms. FEBS Lett 1991; 294: 89-93.

[111] Hara-Hishimura I, Takeuchi Y, Inoue K, Nishimura M. Vesicle transport and processing of the precursor to $2 \mathrm{~S}$ albumin in pumpkin. Plant J 1993; 4: 793-800.

[112] Hiraiwa N, Nishimura M, Hara-Nishimura I. Vacuolar processing enzyme is self-catalytically activated by sequential removal of the C-terminal and N-terminal propeptides. FEBS Lett 1999; 447: 2136.

[113] Earnshaw WC, Martins LM, Kaufmann SH. Mammalian caspases: structure, activation, substrates, and functions during apoptosis. Annu Rev Cell Biol 1999; 68: 383-424.

[114] Nicholson DW, Thornberry N A. Caspases: The killer proteases. Trends Biochem Sci 1997; 22: 299-306.

[115] Wilson KP, Black J-AF, Thomson JA, et al. Structure and mechanism of interleukin-1 beta converting enzyme. Nature 1994; 370: 270-4.

[116] Uren AG, O'Rourke K, Aravind L, et al. Identification of paracaspases and metacaspases: Two ancient families of caspaselike proteins, one of which plays a key role in MALT Lymphoma. Mol Cell 2000; 6: 961-7.

[117] Vercammen D, van de Cotte B, De Jaeger G, et al. Type II metacaspases Atmc4 and Atmc9 of Arabidopsis thaliana cleave substrates after arginine and lysine. J Biol Chem 2004; 279: 4532936.

[118] Hoeberichts FA, ten Have A, Woltering EJ. A tomato metacaspase gene is upregulated during programmed cell death in Botrytis cinereainfected leaves. Planta 2003; 217: 517-22.

[119] Bozhkov PV, Filanova LH, Suarez MF, et al. VEIDase is a principal caspase-like activity involved in plant programmed cell death and essential for embryonic pattern formation. Cell Death Differ 2004; 11: 175-82.

[120] Madeo F, Herker E, Maldener C, et al. A caspase-related protease regulates apoptosis in yeast. Mol Cell 2002; 9: 911-7.

[121] Suarez M, Filonova L, Smertenko A, et al. Metacaspase-dependent programmed cell death is essential for plant embryogenesis. Curr Biol 2004; 14: R339-40.

[122] Bozhkov PV, Suarez MF, Filonova LH, et al. Cysteine protease $m c I I-P a$ executes programmed cell death during plant organogenesis. Proc Natl Acad Sci USA 2005; 102: 14463-8.

[123] Smertenko AP, Bozhkov PV, Filonova L, et al. Re-organisation of the cytoskeleton during developmental programmed cell death in Picea abies embryos. Plant J 2003; 33: 813-24.

[124] Mashima T, Naito M, Tsuruo T. Caspase-mediated cleavage of cytoskeletal actin plays a positive role in the process of morphological apoptosis. Oncogene 1999; 18: 2423-30.
[125] Vercammen D, Belenghi B, van de Cotte B, et al. Serpin1 of Arabidopsis thaliana is a suicide inhibitor for metacaspase $9 . \mathrm{J} \mathrm{Mol}$ Biol 2006; 364: 625-36.

[126] Belenghi B, Romero-Puertas MC, Vercammen D, et al. Metacaspase activity of Arabidopsis thaliana is regulated by Snitrosylation of a critical cysteine residue. J Biol Chem 2007; 282: 1352-8.

[127] Rojo E, Martin R, Carter C, et al. VPE gamma exhibits a caspaselike activity that contributes to defense against pathogens. Curr Biol 2004; 14: 1897-906.

[128] Adams JM, Cory S. Bcl-2 protein family: the arbiters of cell survival. Science 1998; 281: 1322-6.

[129] Merry DE, Korsmeyer SJ. Bcl-2 gene family in the nervous system. Annu Rev Neurosci 1997; 20: 245-67.

[130] Shah NK, Taneja TK, Hasnain SE. Mitochondria can power cells to life and death. Resonance 2000; 5: 74-84.

[131] Bernardi P, Petronilli V, Di Lisa F, Forte M. A mitochondrial perspective on cell death. Trends Biochem Sci 2001; 26: 112-7.

[132] Kroemer G, Reed JC. Mitochondrial control of cell death. Nat Med 2000; 6: 513-9.

[133] Desagher S, Martinou JC. Mitochondria as the central control point of apoptosis. Trends Cell Biol 2000; 10: 369-77.

[134] Zoratti M, Szabo I. The mitochondrial permeability transition. Biochim Biophys Acta 1995; 1241: 139-76.

[135] Birnbaum MJ. On the interaction between hexokinase and the mitochondrion. Dev Cell 2004; 7: 781-2.

[136] Majewski N, Noqueira V, Bhaskar P, et al. Hexokinasemitochondria interaction mediated by Akt is required to inhibit apoptosis in the presence or absence of Bax and Bak. Mol Cell 2004; 16: 819-30.

[137] Azoulay-Zohar H, Israelson A, Abu-Hamad S, Shoshan-Barmatz $\mathrm{V}$. In self-defence: Hexokinase promotes voltage dependent anion channel closure and prevents mitochondria-mediated apoptotic cell death. Biochem J 2004; 377: 347-55.

[138] Nakagawa T, Shimizu S, Watanabe T, et al. Cyclophilin Ddependent mitochondrial permeability transition regulates some necrotic but not apoptotic cell death. Nature 2005; 434: 652-8.

[139] Green DR, Kroemer G. The pathophysiology of mitochondrial cell death. Science 2004; 305: 627-9.

[140] Sugiyama T, Shimizu S, Matsuoka Y, et al. Activation of mitochondrial voltage-dependent anion channel by a proapoptotic $\mathrm{BH} 3-$ only protein Bim. Oncogene 2002; 21: 4944-56.

[141] Lam E, Kato N, Lawton M. Programmed Cell Death, mitochondria and the plant hypersensitive response. Nature 2001; 411: 848-53.

[142] Swidzinski JA, Leaver CJ, Sweetlove LJ. A proteomic analysis of plant programmed cell death. Phytochem 2004; 65: 1829-38.

[143] Van der Biezen EA, Jones JDG. The NB-ARC domain: A novel signalling motif shared by plant resistance gene products and regulators of cell death in animals. Curr Biol 1998; 8: 226-7.

[144] Krause M, Durner J. Harpin inactivates mitochondria in Arabidopsis suspension cells. Mol Plant Microbe Interact 2004; 17: 131-9.

[145] Hoeberichts FA, Woltering EJ. Multiple mediators of plant programmed cell death: Interplay of conserved cell death mechanisms and plant-specific regulators. Bioessays 2002; 25: 47-57.

[146] Burns TF, El-Deiry WS. Identification of Inhibitors of TRAILInduced Death (ITIDs) in the TRAIL sensitive colon carcinoma cell line, SW480, using a genetic approach. J Biol Chem 2001; 276: 37879-86.

[147] Lacomme C, Santa cruz S. Bax induced cell death in tobacco is similar to hypersensitive response. Proc Natl Acad Sci USA 1999; 96: 7956-61.

[148] Qiao J, Mitsuhara I, Yozaki Y, et al. Enhanced resistance to salt, cold \& wound stresses by overproduction of animal cell death suppressors Bcl-xl and Ced-9 in tobacco cells-Their possible contribution through improved function of organelle. Plant Cell Physiol 2002; 43: 992-1005.

[149] Kawai-Yamada M, Jin L, Yoshinaga K, et al. Mammalian Baxinduced plant cell death can be down-regulated by over expression of Arabidopsis Bax inhibitor-1(AtBI-1). Proc Natl Acad Sci USA 2001; 98: 12295-13000.

[150] Bolduc N, Brisson LF. Antisense down regulation of NtBI-1 in tobacco BY-2 cells induces accelerated cell death upon carbon starvation. FEBS Lett 2002; 532: 111-4.

[151] Bolduc N, Ouellet M, Pitre F, Brisson, LF. Molecular characterization of two plant BI-1 homologues which suppress Bax-induced apoptosis in human 293 cells. Planta 2003; 216: 377-86. 
[152] Eichmann, R, Holger S, Kogel K-H, et al. The barley apoptosis suppressor homologue Bax inhibitor-1 compromises nonhost penetration resistance of barley to the inappropriate pathogen Blumeria graminis f. sp. tritici. Mol Plant Microbe Interact 2004; 17: 484-90.

[153] Kawai-Yamada M, Ohmori Y, Uchimiya H. Dissection of Arabidopsis Bax inhibitor-1 suppressing Bax-, hydrogen peroxide-, and salicylic acid-induced cell death. Plant Cell 2004; 16: 21-32.

[154] Yu L-H, Kawai-Yamada M, Naito M, et al. Induction of mammalian cell death by plant Bax inhibitor. FEBS Lett 2002; 512: 30812.

[155] Xu Q, Reed JC. Bax inhibitor-1, a mammalian apoptosis suppressor identified by functional screening in yeast. Mol Cell 1998; 1: 33746.
[156] Matsumura H, Nirasawa S, Kiba A, et al. Overexpression of Bax inhibitor suppresses the fungal elicitorinduced cell death in rice (Oryza sativa L.) cells. Plant J 2003; 33: 425-34.

[157] Huckelhoven R, Dechert C, Kogel KH. Overexpression of barley BAX inhibitor 1 induces breakdown of mlo-mediated penetration resistance to Blumeria graminis. Proc Natl Acad Sci USA 2003; 100: 5555-60.

[158] Watanabe N, Lam E. Arabidopsis Bax inhibitor-1 functions as an attenuator of biotic and abiotic types of cell death. Plant J 2006; 45: 884-94.

[159] Gevaert K, Van Damme P, Ghesquière B, Vandekerckhove J. Protein processing and other modifications analyzed by diagonal peptide chromatography. Biochim Biophys Acta 2006; 1764: 180110 .

(C) Nanda et al.; Licensee Bentham Open.

This is an open access article licensed under the terms of the Creative Commons Attribution Non-Commercial License (http://creativecommons.org/licenses/ by-nc/3.0/) which permits unrestricted, non-commercial use, distribution and reproduction in any medium, provided the work is properly cited. 